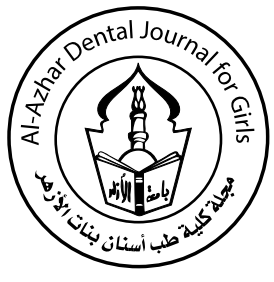

\title{
In-vivo Bond Degradation Resistance and In-vitro Degree of Conversion of Bulk Fill Versus Nano Filled Resin Composite Restoratives
}

\author{
Hend S. Ahmed ${ }^{(1)}$, Maha A. Niazy ${ }^{(2)}$, Mona I. Riad ${ }^{(3)}$ and Asmaa A. Yaseen ${ }^{(4)}$
}

Codex : 05/1701

dentaljournal.forgirls@yahoo.com

\begin{abstract}
Aim: This study was conducted to evaluate bulk fill and nanohybrid resin composite at different cavity depth and after different testing periods.

Materials \& methods: Standardized simple box class II occluso-mesial (OM) cavities were prepared in the selected first maxillary premolar in each quadrant. The cavity depth was adjusted to be either $2 \mathrm{~mm}$ or $4 \mathrm{~mm}$ in each patient. For the bulkfill composite, both the two and four-millimeters cavities, one increment of the resin composite material (Xtra-fil) was packed inside the cavity while for the nanohybrid resin composite (Grandio), the four millimeters cavities were filled incrementally by packing two increments of $2 \mathrm{~mm}$ thickness while for the two millimeters cavities one increment $(2 \mathrm{~mm})$ was packed to fill the cavity and light cured for 20 seconds, finished, polished and left for the assigned time. The restored tooth was extracted atraumatically and teeth were sectioned to produce beam-shaped specimens of $\left(1 \pm 0.1 \mathrm{~mm}^{2}\right)$. The beam specimens were attached with cyanoacrylate gel to fit the Instron Universal testing machine. The tensile load was applied at a cross-head speed of $0.5 \mathrm{~mm} /$ minute until specimen failure occurred. At this point the failure load in Newton was recorded.
\end{abstract}

Results: Cavity depth of $2 \mathrm{~mm}$ showed the highest significant mean microtensile bond strength compared with that of $4 \mathrm{~mm}$. Nanohybrid resin composite showed the highest significant mean micro tensile compared with Bulkfill resin composite. The testing period of 24 hours showed highest significant mean microtensile bond strength that one tested after 3 and 6 months.

Conclusion: (1) cavity depth has an apparent influence on tensile bond strength of the tested restoratives to dentin. (2) Microtensile bond strength of the tested restorations deteriorates by aging.
Bulkfill Resin Composite,

Nannofilled Resin Composite,

Microtensile bond strength.

1. Assistant Lecturer of Operative Dentistry, Faculty of Dentistry, British University in Egypt

2. Professor and Head of Operative Department Faculty of Dental Medicine for Girls, Al Azhar University.

3. Professor of Conservative Dentistry, Faculty of Oral and Dental Medicine, Cairo University.

4. Assistant Professor of Conservative Dentistry, Faculty of Oral and Dental Medicine, Cairo University. 


\section{INTRODUCTION}

Preservation of tooth structures and development of adhesive materials with provision of maximum esthetic and strength requirements, all of these factors increased the use of bonded restorations ${ }^{(1)}$. The resin composite type highly affects the marginal quality and the durability of the restorations. (2) The nanohybrid-based resin composite restorations showed better results with the vertical layering technique ${ }^{(3)}$. Newly developed posterior resin composite material has been introduced, which can be applied by bulk filling of the cavity preparation by increment thickness about $4 \mathrm{~mm}$ without the need for incremental layering ${ }^{(4,5)}$. The packing technique of the resin composite is very important factor that may affect the success or failure of the restoration. Incremental packing of resin composite has been long accepted as a standard technique for placement of resin-composite in cavity preparations for reducing the contraction gap along the margins ${ }^{(6)}$. Bonding efficiency evaluation of different restorative materials is carried out by testing the bond strength to tooth structure (dentin and/or enamel). This is achieved by applying a tensile or shear stress to the bonded specimen and measuring the load per unit area at the time of failure of the bond ${ }^{(7)}$. Nanoleakage may occur at the dentin-resin interface even with the absence of marginal gap. It serves as pathways for water movement within the hybrid layer that affect the durability. Bond degradation of the resin adhesives and materials is well documented in vitro and in vivo. Loss of bond strength is first detectable in the laboratory at 3 months ${ }^{(8)}$. Accordingly, this study was carried out to evaluate the bond degradation resistance in vivo of bulk filled posterior resin composite materials and nanohybrid composite at different cavity depths (either $2 \mathrm{~mm}$ or $4 \mathrm{~mm}$ ) and after different testing periods $(24 \mathrm{~h}, 3$ months and 6 months) as assessed by microtensile bond strength.

\section{MATERIALS AND METHODS}

A total of 36 patients were selected to provide seventy-two sound first maxillary premolars (one in each quarter) that were divided into two groups (36 each) according to the cavity depth (D) either $2 \mathrm{~mm}$ (D1) and $4 \mathrm{~mm}$ (D2). Each group was sub-divided into two subgroups (18 each) according to type of the resin composite used (C) either bulk fill resin composite (C1) or nano-hybrid resin composite (C2). Each subgroup was divided into three classes (6 each) according to the testing periods inside the patient mouth (T) either after 24 hours (T1), three months (T2) and after six months (T3). A standardized simple box class II occluso-mesial (OM) cavities were prepared in premolars in both arch sides. The cavities depth was adjusted to be either $2 \mathrm{~mm}$ or $4 \mathrm{~mm}$ in one patient. While the width was $4 \mathrm{~mm}$. The cavities were prepared using straight fissure carbide bur no. 57 size 010 (Brassler, Savannah, Georgia, USA). A single periodontal probe (Hu-Friedy ${ }^{\circledR}$ Co., Rockwell St. Chicago) was used as a guide for all the cavity dimensions. Standardized Ivory matrix holder no.1 with metal matrix band MS-MA4 designed for premolars (MEBA - Schwer GmbH \& Co. KG, Denkingen, Germany) was applied. After proper isolation, self etch adhesive system (Futura Bond DC; VOCO, Cuxhaven, Germany) was used and applied according to manufacturer instructions. A microhybrid bulk fill resin composite material in one universal shade (Xtra-fil; VOCO,Cuxhaven,Germany) and a nanohybrid resin composite shade A3 (Grandio; VOCO, Cuxhaven, Germany) were used in this study. Regarding the bulk fill type, for the four-millimeters cavities, one large increment of the resin composite material (Xtra-fil) was packed inside the cavity using gold plated instrument $\left(\mathrm{Hu}-\right.$ Friedy $^{\circledR}$ Co., Rockwell St. Chicago) and light cured for 20 seconds. For the two-millimeters cavities, the same procedure was repeated. While for the nanohybrid composite, For the four-millimeter cavities, two separate increments of the resin composite material (Grandio) were packed and cured separately. For the two-millimeter cavities, the same procedure was repeated with one increment for the whole cavity. 
After that the restoration was finished using $15 \mu \mathrm{m}$ grit composhape finishing diamond burs (Intensiv ${ }^{\circledR}$, Viganello-Lugano, Switzerland) then polished using a Sof-Lex ${ }^{\circledR}$ Spiral Wheels (3M ESPE, St.Paul, MN, USA). According to the assigned time for extraction either ( 24 hours, 3 or 6 months), the restored teeth were extracted using posterior periotome instrument (Hu-Friedy Co., Rockwell St.Chicago). For the microtensile testing, each tooth with the bonded resin composite restoration was fixed on acrylic resin blocks of two cm diameter and the occlusal surface of composite restoration was marked with red permanent marker. The acrylic block was fixed in a metal attachment to be fixed to the isomet saw. The crowns were sectioned along the buccolingual and mesio-distal planes using a diamond disk (MTI Corporation, Richmond, CA, USA) in a low speed micro-slicing machine (Isomet, Buehler, Lake Bluff, IL, USA) under water-cooling, to produce beam-shaped specimens of $\left(1 \pm 0.1 \mathrm{~mm}^{2}\right)$ that was checked by digital caliper. The centralized 2 beams were taken from each tooth and so a total of 12 beams were obtained for each class. The bond strength test was performed immediately after cutting. The beam specimens were attached with cyanoacrylate gel (Zapit; Dental Ventures of America, Corona, CA, USA) to the testing customized microtensile jig. This jig is designed to fit the Instron Universal testing machine (Bisco Inc. Schaumburg, IL, USA). The tensile load was applied at a crosshead speed of $0.5 \mathrm{~mm} /$ minute until specimen failure occurred. At this point the failure load in Newton was recorded. The bond strength was calculated as the ratio between the failure load and the beam area to express bond in Mpa.

\section{RESULTS}

1. Effect of cavity depth on the mean microtensile bond strength (MPa) regardless of other variables:

Mean and standard deviation (SD) for the microtensile bond strength (MPa) for different cavity depths regardless of other variables were presented in table (1) and figure (1). A cavity depth of $2 \mathrm{~mm}$ showed highest significant mean microtensile bond strength $(\mathrm{MPa})(22.72 \pm 3.81)$ compared with that of $4 \mathrm{~mm}(21.15 \pm 5.11)$ at $\mathrm{p}=0.001$.

Table (1) Mean and standard deviation (SD) of microtensile bond strength (MPa) for different cavity depths regardless of other variables.

\begin{tabular}{|c|c|c|c|c|c|}
\hline & \multicolumn{3}{|c|}{ Cavity Depth } & \multirow{2}{*}{$\begin{array}{c}\text { p- } \\
\text { value }\end{array}$} \\
\cline { 2 - 5 } & \multicolumn{2}{|c|}{$2 \mathrm{~mm}$} & \multicolumn{2}{|c|}{$4 \mathrm{~mm}$} & \\
\cline { 2 - 5 } & Mean & SD & Mean & SD & \\
\hline $\begin{array}{c}\text { Microtensile bond } \\
\text { strength (MPa) }\end{array}$ & 22.72 & 3.81 & 21.15 & 5.11 & $0.001 *$ \\
\hline
\end{tabular}

*= Significant



Fig. (1) Bar chart showing the mean microtensile bond strength (MPa) for different cavity depths regardless of other variables

\section{Effect of different resin composite restorative} materials on the mean microtensile bond strength (MPa) regardless of other variables:

Mean and standard deviation (SD) for the microtensile bond strength of different resin composite regardless of other variables were presented in table (2) and figure (2). Nanohybrid resin composite showed the highest significant mean microtensile bond strength $(22.27 \pm 4.59)$ compared with Bulkfill resin composite $(21.56 \pm 4.58)$ at $\mathrm{p}=0.009$. 
3. Effect of the testing periods on the mean microtensile bond strength (MPa) regardless of other variables:

Mean and standard deviation (SD) for the microtensile bond strength (MPa) for the testing periods regardless of other variables were presented in table (3) and figure (3). It was shown that there was a significant difference between all testing periods, where microtensile bond strength tested after 24 hrs showed the highest significant mean value of (26.88 \pm 1.48$)$, followed by that tested after 3 months $(21.93 \pm 1.84)$. Whereas the least mean microtensile bond strength values were after 6 months testing pe- $\operatorname{riod}(16.58 \pm 2.13)$

\section{Interaction between variables on mean Micrtensile bond strength (MPa):}

Mean and standard deviation (SD) for the microtensile bond strength (MPa) for different tested variables were presented in table (4) and figure (4). When Nanohybrid resin composite packed in cavities of $2 \mathrm{~mm}$ depths and tested after $24 \mathrm{hrs}$ showed the higher mean value $(27.65 \pm 0.93)$, while when the Bulk fill resin composite packed in cavities of $4 \mathrm{~mm}$ depth and tested after 6 months showed the lowest mean value $(14.45+1.73)$.

Table (2): Mean and standard deviation (SD) of microtensile bond strength (MPa) of different resin composites regardless of other variables

\begin{tabular}{|c|c|c|c|c|c|}
\hline & \multicolumn{4}{|c|}{ Resin Composite } & \multirow{3}{*}{ p-valuc } \\
\hline & \multicolumn{2}{|c|}{ Nanohybrid } & \multicolumn{2}{|c|}{ Bulkfill } & \\
\hline & Mean & SD & Mean & SD & \\
\hline Microtensile bond strength (MPa) & 22.27 & 0.59 & 21.56 & 0.58 & $0.009 *$ \\
\hline
\end{tabular}

*= Significant

Table (3): Mean and standard deviation (SD) of microtensile bond strength (MPa) for testing periods regardless of other variables

\begin{tabular}{|l|c|c|c|c|c|c|c|}
\hline \multirow{2}{*}{} & \multicolumn{9}{|c|}{ Testing periods } & \multirow{2}{*}{ p-value } \\
\cline { 2 - 7 } & \multicolumn{2}{|c|}{24 hrs } & \multicolumn{2}{|c|}{3 Months } & \multicolumn{2}{c|}{6 Months } & \\
\cline { 2 - 8 } & Mean & SD & Mean & SD & Mean & SD & \\
\hline Microtensile Bond Strength (MPa) & $26.88^{\mathrm{a}}$ & 1.48 & $21.93^{\mathrm{b}}$ & 1.84 & $16.58^{\mathrm{c}}$ & 2.13 & $\leq 0.001^{*}$ \\
\hline
\end{tabular}

*= Significant, $N S=$ Non-significant

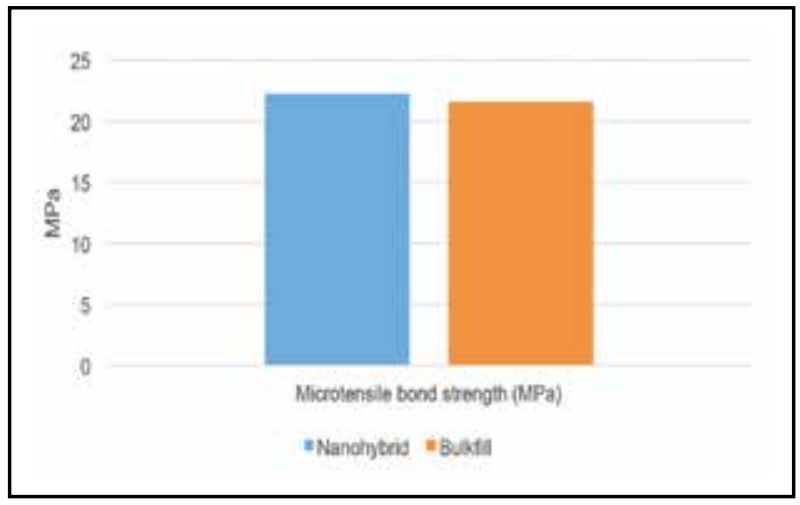

Fig. (2) Bar chart showing the mean microtensile bond strength (MPa) of different resin composites regardless of other variables

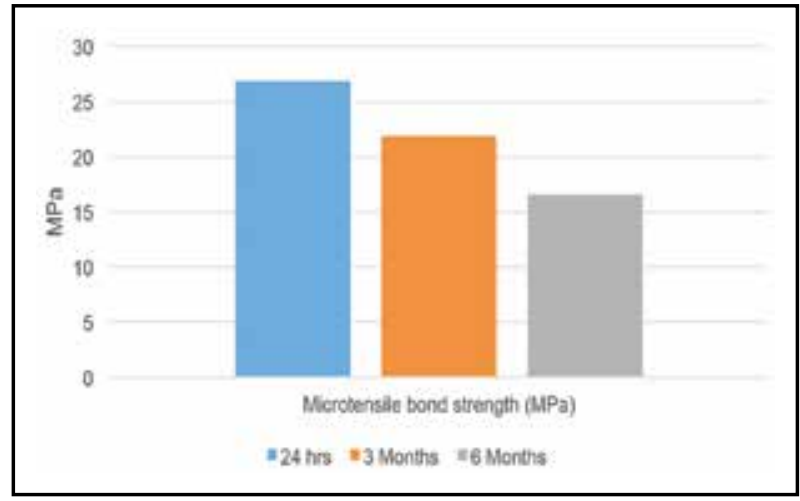

Fig. (3) Bar chart showing the mean micrtensile bond strength (MPa) of testing periods regardless of other variable 
Table (4): Mean and standard deviation (SD) of microtensile bond strength (MPa) for different tested variables in a descending order

\begin{tabular}{|c|c|c|c|c|c|}
\hline & \multirow[b]{2}{*}{ Mean } & \multicolumn{2}{|c|}{ Microtensile Bond Strength (MPa) } & \multirow[t]{2}{*}{ Rank } & \multirow[t]{2}{*}{ p-value } \\
\hline & & SD & & & \\
\hline \multirow{12}{*}{ 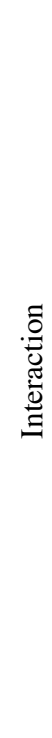 } & $2 \mathrm{~mm}+$ Nanohybrid+24 hrs & 27.65 & .93 & a & \multirow{12}{*}{$\leq 0.001 *$} \\
\hline & $4 \mathrm{~mm}+$ Nanohybrid $+24 \mathrm{hrs}$ & 27.28 & 1.31 & a & \\
\hline & $2 \mathrm{~mm}+$ Bulkfill$+24 \mathrm{hrs}$ & 26.34 & 1.70 & a & \\
\hline & $4 \mathrm{~mm}+$ Bulkfill $+24 \mathrm{hrs}$ & 26.31 & 1.62 & a & \\
\hline & $4 \mathrm{~mm}+$ Nanohybrid +3 Months & 23.00 & 2.33 & $\mathrm{~b}$ & \\
\hline & $2 \mathrm{~mm}+$ Bulkfill+3 Months & 22.37 & 1.84 & $\mathrm{bc}$ & \\
\hline & $2 \mathrm{~mm}+$ Nanohybrid +3 Months & 21.45 & .97 & $\mathrm{bc}$ & \\
\hline & $4 \mathrm{~mm}+$ Bulkfill+3 Months & 20.83 & 1.30 & $\mathrm{c}$ & \\
\hline & $2 \mathrm{~mm}+$ Nanohybrid+6 Months & 18.48 & 0.90 & $\mathrm{~d}$ & \\
\hline & $2 \mathrm{~mm}+$ Bulkfill+6 Months & 18.26 & 1.18 & d & \\
\hline & $4 \mathrm{~mm}+$ Nanohybrid+6 Months & 15.80 & 1.25 & e & \\
\hline & 4 mm+Bulkfill+6 Months & 14.45 & 1.73 & $\mathrm{e}$ & \\
\hline
\end{tabular}

Means with the same letter within each column are non-significantly different at $p=0.05$. * Significant, NS=Nonsignificant

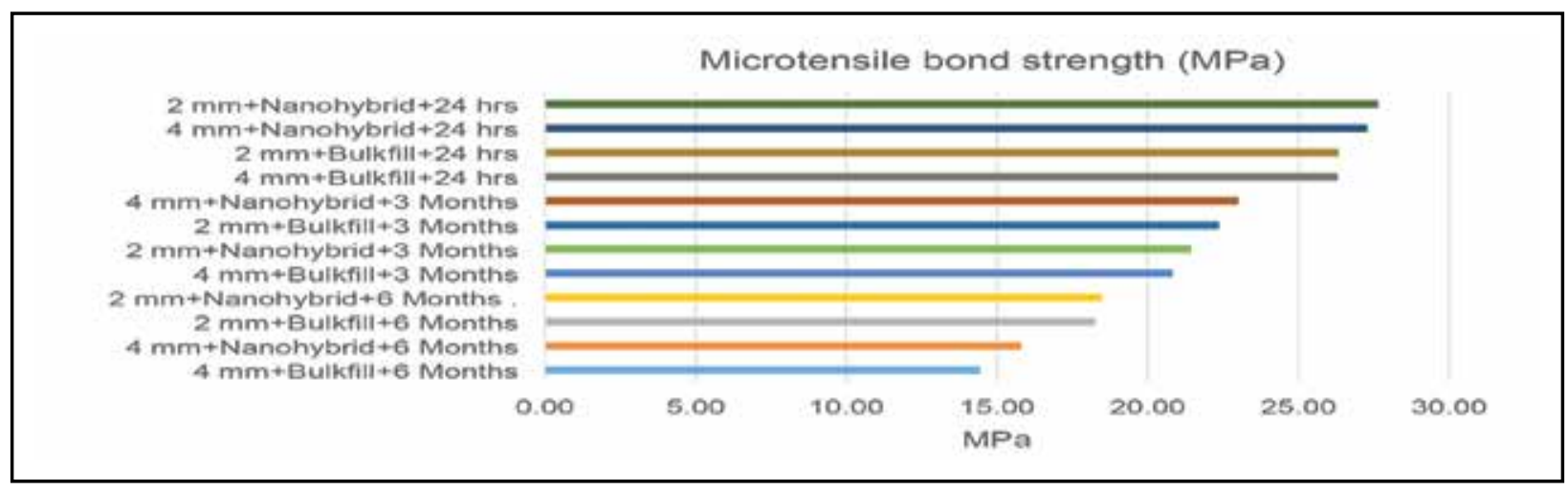

Fig. (4) Bar chart showing the mean microtensile bond strength (MPa) for different tested variables

\section{DISCUSSION}

The durability of bonds between resin and tooth substrates is of significant importance for the clinical longevity of resin bonded restorations. Bonding to enamel is thought to be reliable and durable, especially using etch-and-rinse adhesives. On the contrary, the long-term stability of resin-bonded dentin remains questionable. In vitro laboratory studies reported decreases in dentin bond strength after long-term storage in water. Although in vivo long-term durability studies reported the degradation of hybrid layers over time, they are still limited with respect to number and adhesive type ${ }^{(9,10)}$. Regarding the effect of cavity depth on mean microtensile bond strength regardless of other variables, a cavity depth of $2 \mathrm{~mm}$ showed highly 
significant difference in the mean microtensile bond strength than that one tested at $4 \mathrm{~mm}$ depth. This might be attributed to the ability of light to pass and reach the whole thickness of the packed $2 \mathrm{~mm}$ increment ${ }^{(11)}$ obtaining maximum polymerization with consequent improvement of the bond strength ${ }^{(12)}$. Moreover, the high bond strength at $2 \mathrm{~mm}$ depth might be due to the fact that bonding to superficial dentin is better than that to deep dentin. At the superficial dentin, the hybrid layer formation is more than resin tags as the number of dentinal tubules in proportion to inter-tubular dentin is lesser than that at deep dentin ${ }^{(13)}$. These findings were in agreement with several authors ${ }^{(14-18)}$. On the other hand, these findings were in disagreement with Lopes et al, $2009{ }^{(19)}$ who concluded that bond strength to deep dentin in vivo was similar to shallow dentin. This might be due to differences in study conditions. As they prepared class I cavities that were confined with walls from all sides. In addition, they used etch and rinse adhesives not self etch ones. Moreover, they assessed the bond strength after one week and 4 weeks post insertion periods. Concerning the effect of different resin composites on mean microtensile bond strength regardless of other variables, the Nanohybrid resin composite showed the highest significant mean microtensile bond strength compared with Bulkfill resin composite. This might be due to the incremental packing technique that was used with the nanohybrid composite. The incremental packing allowed for better polymerization of the resin composite as the increment thickness did not exceed $2 \mathrm{~mm}$ which is the recommended thickness for most of the used types of composite. This was in agreement with (Price et al, 2000 and Ghavamnasiri et al, 2007) ${ }^{(20,21)}$. Oppositely, these findings were in disagreement with Furness et al, 2014 and Webber et al, 2014 ${ }^{(22,23)}$. This contradiction might be attributed to using different approach of adhesive as they used etch and rinse approach. Additionally, they tested their materials extra-orally (in vitro) depending on thermocycling to simulate the oral cavity conditions. Moreover, concerning Furness et al, they worked on class I cavities that is completely different of class II preparations. While for Webber et al, they used flowable bulkfill composite with better flowability and maximum adaptation and bond strength. Regarding the effect of the post insertion periods on mean Microtensile bond strength regardless of other variables, the bond strength after 24 hours showed highest significant mean value followed by significant decrease after 3 months followed by a further significant decrease after 6 months. This could be explained due to the bio-degradation process of resin based materials, as the plasticization effect is recognized to affect all properties after few months of application ${ }^{(24,25)}$. In addition, the daily rate of consumption of aqueous solutions inside the oral cavity can not be neglected as long as the role of water sorption which drastically affects the micro tensile bond strength of the resin based materials used. Since the hydrophilic adhesives tend to rapidly absorb water, owing to their chemical composition of lower filler content ${ }^{(26)}$, which results in polymer swelling, plasticizing and weakening of the polymer network. It is possible that these changes would make resin-dentin interface created by hydrophilic self-etch adhesives much more unstable over time. Thus, adhesives within hybrid layer could affect the long-term durability of resin-dentin bond ${ }^{(27-29)}$. As the self-etch adhesive might absorb the water from dentinal tubules during bonding by osmosis, leading to nano-leakage formation with a subsequent decline in the bond strength. This was also supported by other studies that have shown that water trees, water bubbles and phase separation occurred in the adhesive interface of self etch adhesives. These results were in agreement with many authors ${ }^{(30-33)}$ stating that resin/dentin bonds degrade overtime. Many factors can cause the degradation; among them are exposure to water, incomplete hybridization and residual solvent of the adhesive ${ }^{(34)}$. Manso et al in $2008^{(35)}$, reported that the adhesive dentin bond strength was significantly 
reduced after 3 months of water storage. It was suggested that bond durability might be related to both compositional differences of adhesive systems and their ability to completely infiltrate the de-mineralized dentin matrix ${ }^{(36)}$.These findings were contradicted with Belli et al, $201{ }^{(37)}$ who reported high bond stability for all the adhesives used after one year with no statistically different bond strength values measured at 24 hours. This contradiction might be attributed to difference in the nature of the study as it was in vitro study without all the conditions of oral environment that favor the composite biodegradation. Moreover, another attribution might be presence of enamel margins in the cavity preparations. Enamel margins were effective in preventing water infiltration from wet environments, protecting the inner dentin substrate from water degradation. Additionally, Martins et al $2009^{(38)}$ also disagreed with the findings of the present study as they observed no degradation of the bond strength after 6 months of water storage.

\section{CONCLUSION}

Under the limits of the present study it could be concluded that cavity depth has an apparent influence on bond strength of the tested restoratives to dentin. In addition, the improved bonding quality of both tested materials with their different application techniques during the initial testing period deteriorates with aging. Finally, the bulkfill composite wih self-etch adhesive system might be successfully adapted to optimize the bond strength of resin composite to dentin.

\section{REFERENCES}

1. Rosenstiel SF, Land MF and Crispin BJ. Dental luting agents: a review of the current literature. J Prosthet Dent. 1998; 80(3):280-301.

2. Roggendorf MJ, Kra N, Appelt A, Naumann M and Frankenberger R. Marginal quality of flowable 4-mm base versus conventionally layered resin composite. Oper. Dent. 2011; 39(10):643-7.
3. Baig MM, Mustafa M, Al Jeaidi ZA and Al-Muhaiza M. Microleakage evaluation in restorations using different resin composite insertion techniques and liners in preparation with high c-factor - An in vitro study. KSU J Dent Scie. 2013; 4(2):57-64.

4. Figueiredo A, Giannini M, Ambrosano G M and Chan D C. The effects of filling techniques and a low-viscosity composite liner on bond strength to class II cavities. J Dent. 2003; 31(1): 59-66.

5. Moorthy A, Hogg C, Dowling H, Grufferty BF, Benetti R and Fleming G. Cuspal deflection and microleakage in premolar teeth restored with bulk-fill flowable resin-base composite base materials. J. Dent. 2012; 40(6):500-5.

6. Pilo R, Oelgiesser D and Cardash HS. A survey of output intensity and potential for depth of cure among light-curing units in clinical use. J Dent. 1999; 27:235-41.

7. Burrow MF, Nopnakeepong U and Phrukkanon S. A comparison of microtensile bond strengths of several dentin bonding systems to primary and permanent dentin. Dent Mat. 2002; (18): 239-45.

8. De Munck J, Van LK, Peumans M, Poitevin A, Lambrechts P, Braem M and Van Meerbeek B. A critical review of the durability of adhesion to tooth tissue: methods and results. J Dent Res. 2005; 84:118-32.

9. Koshiro K, Inoue S, Tanaka T, Koase K, Fujita M and Hashimoto M. In vivo degradation of resin-dentin bonds produced by a self- etch vs. a total-etch adhesive system. Eur J Oral Sci. 2004; 112:368-75.

10. Mutluay MM, Yahyazadehfar M, Ryou H, Majd H, Do D and Arola D. Fatigue of the resin-dentine interface: a new approach for evaluating the durability of dentine bonds. Dent mater. 2013; 29(4):437-49.

11. Giachetti L, Scaminaci RD and Bambi C. A review of polymerization shrinkage stress: current techniques for posterior direct resin restorations. J Contemp Dent Pract. 2006; 7(4):79-88.

12. Son SA, Roh HM, Hur B, Kwon YH and Park JK. The effect of resin thickness on polymerization characteristics of silorane-based composite resin. Restor Dent Endo. 2014; 39(4):310-8.

13. Singh K, Naik R, Hegde S and Damda A. shear bond strength of superficial, intermediate and deep dentin in vitro with recent generation self-etching primers and single nano composite resin. J Int Oral Health 2015; 7(1):28-32. 
14. Pashley EL, Tao L, Matthews W.G and Pashley D.H. Bond strengths to superficial, intermediate and deep dentin in vivo with four dentin bonding systems. Dent Mater. 1993; 9(1):19-22.

15. Purk JH, Dusevich V, Glaros A, Spencer P and Eick AD. In vivo versus in vitro microtensile bond strength of axial versus gingival cavity preparation walls in class II resin based composite restorations. Americ Dent Associa. 2004; 135:185-93.

16. Pegado RE, Amaral FL, Floro FM and Basting RT. Effect of Different Bonding Strategies on Adhesion to Deep and Superficial Permanent Dentin. Euro J Dent. 2010; 4(2):110-17.

17. He Z, Shimada Y, Sadr A, Ikeda M and Tagami J. The effects of cavity size and filling method on the bonding to Class I cavities. J Adhes Dent. 2008; 10(6):447-53.

18. Zhang L, Wang D, Fan J, Li F, Chen Y and Chen J. Stability of bonds made to superficial vs. deep dentin, before and after thermocycling. Dent Mater. 2014; 30(11):1245-51.

19. Lopes GC, Corra A and Oliveira G. Microtensile bond strength invivo: effect of cavity depth. J Dent. 2009; 37(2):1-7.

20. Price RB, Doyle G and Murphy D. Effects of Composite Thickness on the Shear Bond Strength to Dentin. J Cand Dent Assoc. 2000; 66(1):35-9.

21. Ghavamnasiri M,Moosavi H and Tahvildarnejad N. Effect of centripetal and incremental methods in class II composite resin restorations on gingival microleakage. J Contemp Dent Pract. 2007; 8(2):1-7.

22. Furness A,Yousef M, Looney SW and Rueggeberg FA. Effect of bulk / incremental fill on internal gap formation of bulk-fill composites. J Dent. 2014; 42(4):439-49.

23. Webber MB, Marin GC, Progiante PS, Lolli LF and Marson FC. Bulk fill resin based composites: microleakage of class II restorations. J Surg and Clinic Dent. 2014; 2(1):15-9.

24. Paul SJ, Leach M, Rueggeberg FA, Pashley DH. Effect of water content on the physical properties of model dentine primer and bonding resins. J Dent. 1999; 27:209-14

25. Yiu CK, King NM, Pashley DH, Suh BI, Carvalho RM and Carrilho MR. Effect of resin hydrophilicity and water storage on resin strength. J Biomat. 2004; 25:5789-96.

26. Bayne SC, Thompson JY, Swift EJJ, Stamatiades P and Wilkerson M. A characterization of first-generation flowable composites. J Am Dent Ass. 1998; 129:567-77.
27. Carrilho MRO, Carvalho RM, Tay FR and Pashley DH. Effect of storage media on mechanical properties of adhesive systems. Amer J of Dent. 2004; 17:104-8.

28. Yoshida Y, Nagakane K, Fukuda R, Nakayama Y, Okazaki $\mathrm{M}$ and Shintani. Comparative study of adhesive performance of functional monomers. J Dent Res. 2004; 83:454-8.

29. Kitasako Y, Burrow MF, Nikaido T and Tagami J. The influence of storage solution on bond durability of resin cement. Dent Mater.2000; 16:1-6.

30. Loguercio AD, Stanislawczuk R, Mena-Serrano A and Reis A. Effect of three-year water storage on the performance of one-step self etch adhesives applied actively on dentine. J Dent. 2011; 39(8):578-87.

31. Hamouda IM, Samra NR and Badawi MF. Microtensile bond strength of etch and rinse versus self-etch adhesive systems. J Mech Behav Biomed Mat. 2011; 4(3):461-6.

32. Manso AP, Marquezini Jr L, Silva SM, Pashley DH, Tay FR and Carvalho RM. Stability of wet versus dry bonding with different solvent-based adhesives. Dent Mater. 2008; 24(4):476-82.

33. Poitevin A, De Munk J, Ende AV, Suyama Y, Mine A, Peumans $M$ and Van Meerbeek B. Bonding effectiveness of self adhesive composites to dentin and enamel. Dent Mater. 2013; 29(2): 221-30.

34. Toledano M, Osorio R, de Leonardi G, Rosales-Leal, JI, Ceballos L and Cabrerizo-Vilchez MA. Influence of selfetching primer on the resin adhesion to enamel and dentin. Am J Dent. 2001; 14(4):205-10.

35. Manso AP, Marquezini JrL, Silva SM, Pashley DH, Tay FR and Carvalho RM. Stability of wet versus dry bonding with different solvent-based adhesives. Dent Mater. 2008; 24(4):476-82.

36. Hashimoto M, De Munck J, Ito S, Sano H, Kaga M, Oguchi H, Van Meerbeek B and Pashley DH. In vitro effect of nanoleakage expression on resin-dentin bond strengths analyzed by microtensile bond test, SEM/EDX and TEM. Biomat. 2004; 25: 5565-74.

37. Belli R, Sartori N, Peruchi LD, Guimaraes JC, Araujo E, Monterio JRS, Baratieri LN and Lohbauer U. Slow progression of dentin bonding degradation during one-year water storage under stimulated pulpal pressure. J Dent. 2010; 38(10): 802-10.

38. Martins GC, Cailxto AL, Gomes OMM, Loguercio AD, D'Alpino PHP and Reis A. Effect of water storage on resin- dentin bond strengths formed by different bonding approaches. Indian J Dent Res. 2009; 20(4):431-6. 